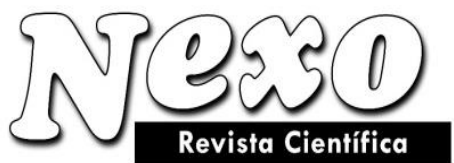

\title{
An energy method for computing the use of fossil fuel energy
}

\section{Un método energético para calcular el uso de energía de combustibles fósiles}

\author{
Timur B. Temukuyev \\ Russian Presidential Academy of National Economy and Public Administration under the President of \\ the Russian Federation. Moscow, Russia. \\ energoconsul@mail.ru
}

(recibido/received: 28-octubre-2020; aceptado/accepted: 15-enero-2021)

\begin{abstract}
An energy method for computing the use of fossil fuel energy has been considered in the article. On the world market, the fuel price depends on supply and demand and involves no energy costs for fuel production. An energy analysis of economic activity was suggested by Charles Hall, an American scientist, who introduced a notion of Energy Returned on Energy Invested, as a ratio between returned and invested energy, into scientific discourse. No account has been taken of invested energy depreciation in this method. All losses are fully incorporated, when the ratio between beneficially used energy in all process flow chains from fuel deposit exploration to energy utilisation, and the considered amount of natural fuel primary energy is taken as the coefficient of beneficial primary energy use (CBPEU). When CBPEU is determined, allowance is made for all potential energy losses; the depreciation degree of energy, contained in the fuel, from its deposit to a consumer, is defined. When energy of renewable sources is utilised, a coefficient of renewable sources energy conversion, defined as the ratio between energy delivered by a power unit throughout the entire operation period, and invested energy taking into account CBPEU over the same period, will represent an objective criterion of power unit efficiency.
\end{abstract}

Keywords: coefficient of beneficial primary energy use; fuel reprocessing; fuel transportation; energy breeding gain.

\section{RESUMEN}

En el artículo se ha considerado un método energético para calcular el uso de energía de combustibles fósiles. En el mercado mundial, el precio del combustible depende de la oferta y la demanda y no implica costos de energía para la producción de combustible. Charles Hall, un científico estadounidense, sugirió un análisis energético de la actividad económica, quien introdujo una noción de energía devuelta sobre energía invertida, como una relación entre energía devuelta e invertida, en el discurso científico. No se ha tenido en cuenta la depreciación de la energía invertida en este método. Todas las pérdidas se incorporan por completo, cuando la relación entre la energía beneficiosa usada en todas las cadenas de flujo del proceso desde la exploración de depósitos de combustible hasta la utilización de energía, y la cantidad considerada de energía primaria de combustible natural se toma como el coeficiente de uso de beneficioso de energía primaria (CBPEU). Cuando se determina el CBPEU, se tienen en cuenta todas las pérdidas de energía potenciales; Se define el grado de depreciación de la energía contenida en el combustible, desde su depósito hasta el consumidor. Cuando se utiliza energía de fuentes renovables, un coeficiente de conversión de energía de fuentes renovables, definido como la rela- 
ción entre la energía entregada por una unidad de potencia durante todo el período de operación y la energía invertida teniendo en cuenta el CBPEU durante el mismo período, representará un criterio objetivo. de eficiencia de la unidad de potencia.

Palabra clave :coeficiente de uso de beneficioso de energía primaria; reprocesamiento de combustible; transporte de combustible; ganancia de generación de energía.

\section{INTRODUCTION}

On the worldwide market, the price of fossil fuel, as the price of any product, mostly depends on its quality, supply, and demand. Since market competition principles underlie the international pricing policy, the goods production costs, which are generally defined by one of the world currencies or national currency unit, constitute solely a seller's problem.

If the processes of producing and selling goods are considered in terms of energy, evaluative computations will become more complex. In conditions of the existing international commerce system, the energy computation method that can be implemented only within a particular country, where there are unified laws and regulations, may basically be of interest only to government institutions, who define the technology-related policy.

\section{MATERIALS AND METHODS}

A deposit most commonly contains two types of fuel, for instance, coal and methane, natural gas and gas condensate, petroleum, and associated petroleum gas. Here, only one component is principal for deposit developers.

The total amount of primary energy within the deposit of fossil fuel found from carried out geological exploration, will be determined by formula, $\mathrm{J}$ :

$$
\sum \boldsymbol{Q}_{\mathrm{o}}=\sum_{i=1}^{n} \boldsymbol{B}_{\boldsymbol{i}} \cdot \boldsymbol{Q}_{H i}^{p}
$$

where $\boldsymbol{B}_{\boldsymbol{i}}$ - estimated reserves of the $i^{\text {th }}$ fuel, $\mathrm{kg}, \mathrm{m}^{3}$;

$\boldsymbol{Q}_{\boldsymbol{H} i}^{\boldsymbol{p}}$ - higher heating value of the $i^{\text {th }}$ fuel, $\mathrm{J} / \mathrm{kg}, \mathrm{J} / \mathrm{m}^{3}$;

$\boldsymbol{n}$ - number of components.

The stage of geological exploration involves the initiation of technical processes that result in reducing the fuel energy value.

It is geological exploration energy costs $\sum \boldsymbol{Q}_{\boldsymbol{g} . \boldsymbol{s}}$, J first. They can be deducted from the total amount of primary energy or taken into account as other losses, on conversion to the design unit of main fuel component, $\mathrm{J} / \mathrm{kg}, \mathrm{J} / \mathrm{m}^{3}$, by formula:

$$
\boldsymbol{Q}_{\boldsymbol{g . s}}=\frac{\sum \boldsymbol{Q}_{\text {g.s. }}}{\sum_{i=1}^{n} \mathrm{~B}}
$$

where $\boldsymbol{B}$ - main component of fuels.

When computing, the heating value of the main fuel component will decrease by the corresponding value.

If there are two in-place components, and only one is used, its reduced heating value will be greater than the intrinsic; it will be defined by the following formula:

$$
\boldsymbol{Q}_{\Pi}^{\mathrm{o}}=\frac{\sum \boldsymbol{Q}_{\mathrm{o}}}{\mathrm{B}},
$$


where B - design amount of main natural fuel situated deep in the earth, $\mathrm{kg}, \mathrm{m}^{3}$.

Unused energy of extracted subterranean fuel should be classified as extraction losses. It is determined as the difference between heating value of natural fuel composition and higher heating value of operating composition of the main fuel component:

$$
\Delta Q_{2}=Q_{\Pi}^{\mathrm{o}}-Q_{H}^{\mathrm{p}}
$$

Associated petroleum gas and flammable gas condensate are typically not used.

If the Earth's interior contains only one component without combustible admixtures, which are lost during fuel extraction, then $\boldsymbol{Q}_{\Pi}^{o}=\boldsymbol{Q}_{\boldsymbol{H}}^{\mathrm{p}}$, and formula (1) will be as follows:

$$
\sum \boldsymbol{Q}_{\mathrm{o}}=\boldsymbol{B} \cdot \boldsymbol{Q}_{\boldsymbol{H}}^{p}
$$

Energy efficiency indicator:

1. EROEI (energy returned on energy invested) is the ratio between obtained and invested energy:

2 .

$$
\operatorname{Er}=\frac{E_{2}}{E_{1}}
$$

where $\boldsymbol{E} \boldsymbol{r}$ - EROEI;

$\boldsymbol{E}_{2^{-}}$energy obtained from fuel or a device transforming the Earth's, solar, etc. energy, J;

$\boldsymbol{E}_{\mathbf{1}}-$ energy expended to extract (produce) energy $\boldsymbol{E}_{\mathbf{2}}, \mathrm{J}$.

2. EROI (energy return on investment) is the ratio between obtained energy and investments, $\mathrm{J} / \mathrm{rub}$.:

$$
E i=\frac{E_{2}}{C},
$$

where $\boldsymbol{E} \boldsymbol{i}$ - EREI;

$\boldsymbol{E}_{2}-$ the same as in formula (6):

$\boldsymbol{C}$ - means spent to extract (produce) energy $\boldsymbol{E}_{2}$, rub.

Let the coefficient of beneficial primary energy use (CBPEU) be the ratio between beneficially used energy at a certain stage of the process flow from exploring fuel deposit to utilising energy $\boldsymbol{Q}_{\boldsymbol{i}}$ (in mass or volume unit equivalent) and the considered amount of natural fuel primary energy $\boldsymbol{Q}_{\Pi}^{\circ}$ :

$$
\mu_{o i}=\frac{Q_{i}}{Q_{H}^{\circ}}
$$

When determining CBPEU, not only energy loss during operation, but also energy losses on the unit creation, assembly, subsequent dismantling, etc., i.e. all possible energy losses should be taken into account. Actually, these are the computations of how subterranean fuel energy is depreciated until it reaches consumers in the form of electricity or heat and is used by them.

With such a method of estimation, CBPEU of the entire system from fuel extraction to energy use will be defined by the following formula:

$$
\mu_{o 1}=\frac{Q_{1}}{Q_{\Pi}^{0}}
$$

where $\boldsymbol{Q}_{\mathbf{1}}$ - beneficially used energy, $\mathrm{J} / \mathrm{kg}, \mathrm{J} / \mathrm{m}^{3}$. 
In general, total primary energy costs, $\mathrm{J} / \mathrm{kg}, \mathrm{J} / \mathrm{m}^{3}$, for a particular stage, can be presented as follows:

$$
\sum Q_{c i}=\sum_{i=1}^{n} Q_{c i}^{c}+\sum_{i=1}^{n} Q_{c i}^{u t}+\sum_{i=1}^{n} Q_{c i}^{o p}+\sum_{i=1}^{n} Q_{c i}^{s a l}+\sum_{i=1}^{n} Q_{c i}^{o t h},
$$

where $\sum_{i=1}^{n} Q_{c i}^{c}$ - total primary energy expended on the object capital construction, equipment assembly and disassembly;

$\sum_{i=1}^{n} Q_{c i}^{u t}$ - total primary energy expended on the equipment fabrication and utilisation;

$\sum_{i=1}^{n} \boldsymbol{Q}_{c i}^{\boldsymbol{o p}}$ - total operational primary energy costs;

$\sum_{i=1}^{n} Q_{c i}^{s a l}$ - total primary energy costs related to people's work and their salary paid;

$\sum_{i=1}^{n} Q_{c i}^{o t h}-$ other total primary energy costs.

Only operational costs will be defined rather easily; the costs related to people's work are very complicated to calculate, since it is fairly difficult to transform them into heat or energy. It will require the development of a special methodology.

Technological system from fuel extraction to electrical and heat energy use can be divided into several processes: extraction, reprocessing, and transportation of fuel, generation, transportation, distribution, consumption of electrical and heat energy. When needed, any of these processes can be divided into parts.

Let the total energy costs be denoted at:

$\sum \boldsymbol{Q}_{\boldsymbol{c} 2}-$ fuel extraction and preparation;

$\sum \boldsymbol{Q}_{c 3}$ - fuel transportation and storage;

$\sum \boldsymbol{Q}_{\boldsymbol{c}}$ - fuel reprocessing;

$\sum \boldsymbol{Q}_{c 5}$ - conversion into other types of energy;

$\sum \boldsymbol{Q}_{\boldsymbol{c} 6}$ - transmission of electrical and heat energy;

$\sum \boldsymbol{Q}_{\boldsymbol{c} 7}$ - distribution of electrical and heat energy;

$\sum \boldsymbol{Q}_{c \mathbf{8}}-$ use (consumption) of electrical and heat energy.

Then the absolute amount of the fuel energy available will accordingly be determined by formulas (11-13). For fuel after:

extraction and preparation

$$
\boldsymbol{Q}_{2}=\boldsymbol{Q}_{\Pi}^{\mathrm{o}}-\sum \boldsymbol{Q}_{c 2}
$$

transportation and storage

$$
\boldsymbol{Q}_{3}=\boldsymbol{Q}_{\Pi}^{\circ}-\left(\sum \boldsymbol{Q}_{c 2}+\sum \boldsymbol{Q}_{c 3}\right)
$$

reprocessing

$$
\boldsymbol{Q}_{4}=\boldsymbol{Q}_{\Pi}^{\circ}-\left(\sum \boldsymbol{Q}_{c 2}+\sum \boldsymbol{Q}_{c 3}+\sum \boldsymbol{Q}_{c 4}\right) .
$$

The fuel as it is with such available energy $\boldsymbol{Q}_{\mathbf{4}}$ is delivered for conversion into other types of energy electrical and heat. The absolute amount of primary energy allowing for previous costs will be determined by formulas $(14-17)$ :

after conversion into other types of energy

$$
\boldsymbol{Q}_{5}=\boldsymbol{Q}_{\Pi}^{\mathrm{o}}-\left(\sum \boldsymbol{Q}_{c 2}+\sum \boldsymbol{Q}_{c 3}+\sum \boldsymbol{Q}_{c 4}+\sum \boldsymbol{Q}_{c 5}\right) ;
$$

after transportation by trunk transmission lines (pipelines)

$$
\boldsymbol{Q}_{6}=\boldsymbol{Q}_{\Pi}^{o}-\left(\sum \boldsymbol{Q}_{c 2}+\sum \boldsymbol{Q}_{c 3}+\sum \boldsymbol{Q}_{c 4}+\sum \boldsymbol{Q}_{c 5}+\sum \boldsymbol{Q}_{c 6}\right)
$$


after transportation by distribution electrical transmission lines (pipelines)

$$
\boldsymbol{Q}_{7}=\boldsymbol{Q}_{\Pi}^{\circ}-\left(\sum \boldsymbol{Q}_{c 2}+\sum \boldsymbol{Q}_{c 3}+\sum \boldsymbol{Q}_{c 4}+\sum \boldsymbol{Q}_{c 5}+\sum \boldsymbol{Q}_{c 6}+\sum \boldsymbol{Q}_{c 7}\right)
$$

beneficially used

$$
\boldsymbol{Q}_{1}=\boldsymbol{Q}_{\Pi}^{\circ}-\left(\sum \boldsymbol{Q}_{c 2}+\sum \boldsymbol{Q}_{c 3}+\sum \boldsymbol{Q}_{c 4}+\sum \boldsymbol{Q}_{c 5}+\sum \boldsymbol{Q}_{c 6}+\sum \boldsymbol{Q}_{c 7}+\sum \boldsymbol{Q}_{c 8}\right) .
$$

To obtain dimensionless values $\boldsymbol{q}_{\boldsymbol{i}}$, denoting respective shares of losses, both parts of equation (17) should be divided by $\boldsymbol{Q}_{\Pi}^{\mathrm{o}}$, then formula (17) will be written as:

$$
\begin{array}{r}
q_{01}=1-\left(q_{2}+q_{3}+q_{4}+q_{5}+q_{6}+q_{7}+q_{8}\right) \\
\text { or } \\
\mu_{01}=1-\left(q_{2}+q_{3}+q_{4}+q_{5}+q_{6}+q_{7}+q_{8}\right),
\end{array}
$$

i.e. CBPEU for a consumer of electrical (heat) energy is obtained.

Formulas $(11-16)$ can be rewritten correspondingly.

CBPEU is an indicator that reflects the effectiveness of using energy resources at all stages of the process flow, from fuel extraction to energy consumer inclusive. If needed, it can be calculated for several consecutive stages of energy consumption.

\section{LITERATURE REVIEW}

In the late XIX century, S.A. Podolinsky, the Russian scientist, was the first to examine life problems in the energy-related context (Podolinsky, 1880). Commenting on his work, F. Engels noted what problems scientists can face when examining this matter (Marx, 1955-1981). In 1886, L. Boltzmann proposed a thermodynamic analysis of life phenomena (Boltzmann, 1970). Russian academics had their own ideas and suggestions. In 1901, N.A. Umov put forward an idea of the third law of thermodynamics, which would determine the specifics of energy processes in life phenomena (Umov, 1916). K.A. Timiryazev (1948) analysed specific thermodynamic functions of chlorophyll apparatus in plants V.I. Vernadsky (1928) offered to introduce some general unit 'to quantitatively compare all natural productive forces. N.M. Fedorovsky (1935) suggested that mineral resources be classified based on energy principle. A.E. Fersman (1937) employed energy method in his research studies. The issues of economic activity energy analysis interested P.G. Kuznetsov (1994).

In 1956, King Hubbert, an American scientist, deduced a formula for extracting petroleum in USA. The extraction first rises then remains unchanged for a while, and then starts to be down. At the first and second stages petroleum is cheap, and at the third stage its price begins to raise (King Hubbert, 1956).

An American biologist Charles Hall proposed a theory of economic activity energy analysis. He introduced a concept of Energy Returned On Energy Invested (EROEI) into scientific use, asserting that predators cannot expend more energy than they receive while hunting. Hall further transferred this idea to petroleum extraction. He divided the amount of energy contained in extracted petroleum by the amount of energy expended on its extraction. Hall, through comparing such indicators of various fields, determined the most perspective of them in terms of energy (Hall, 2008).

In Russia, researchers under the guidance of A.F. Safronov computed EROEI (ratio between obtained and invested energy) of a specific gas condensate field (Safronov, 2010, 2011), and examined its influence on the CBPEU value (Temukuyev, 2014); the EROI value for coal was determined in Ukraine (Cherevatskyi, 2017). 
To date, closer attention has been given to using alternative energy sources, what is largely due to their increased efficiency. Hence, the research on increasing the efficiency of using unconventional power sources has become highly relevant. The use of such unconventional sources as energy obtained by employing biotechnologies can be considered among the most appropriate trends for economies (Fiapshev et al., 2017, 2018). Rather representative is comparison between EROI for wind and solar photovoltaic power systems (Raugei et al., 2017). As time passes, the attitude towards alternative fuel types changes (IPCC, 2018). It becomes apparent that in future, the EROI values of fossils of most renewable energy sources will decrease (Järvensivu et al., 2018), and the future energy balance can change significantly (Moriarty \& Honnery, 2019). A new methodology for estimating EROI (Capellán-Pérez et al., 2019) and standard (De Castro and Capellán-Pérez, 2020) were developed. It is not certain that EROI will be the main decisive factor in the future (Hall, 2017), at the same time a new approach to calculating "corporate" EROI is under review (Celi et al., 2018).

\section{RESULTS}

\subsection{Method for determining a coefficient of renewable sources energy conversion (CRSEC)}

When utilising the energy of renewable resources, CRSEC should be taken as an objective power plant (power unit) efficiency criterion, defined by formula:

$$
\pi=\frac{Q_{1}}{Q_{p e c}}
$$

where $\boldsymbol{Q}_{\mathbf{1}}$ - energy, supplied by power plant (power unit) over the entire operation period;

$Q_{p e c}-$ primary energy costs (imported energy allowing for CBPEU), obtained from an external source over the entire period of its operation.

They are defined as follows:

$$
Q_{p e c}=Q_{e q}+Q_{c a p}+Q_{o p}+Q_{o t h}
$$

where $\boldsymbol{Q}_{\boldsymbol{e q}}$ - primary energy costs to manufacture the equipment;

$\boldsymbol{Q}_{\boldsymbol{c a p}}$ - primary energy expended on capital construction, object equipment assembly and disassembly;

$\boldsymbol{Q}_{\boldsymbol{o p}} \boldsymbol{p}^{-}$operational primary energy costs;

$\boldsymbol{Q}_{\text {oth }}$ - other total primary energy costs.

Other costs should also include labour costs.

If total energy costs $\boldsymbol{Q}_{\boldsymbol{i}}$ are to the power unit operation time $\boldsymbol{\tau}$, then specific primary energy losses $\boldsymbol{q}_{i}=\frac{\boldsymbol{Q}_{i}}{\tau}$, and $\pi=\frac{\boldsymbol{q}_{i}}{\boldsymbol{q}_{p e c}}$.

Power unit efficiency factor will be defined by formula:

$$
\eta=\frac{Q_{u n}}{Q_{\max }}
$$

where $\boldsymbol{Q}_{\boldsymbol{u} \boldsymbol{n}^{-}}$energy supplied by the power unit to an external consumer;

$\boldsymbol{Q}_{\max }$ - maximum energy theoretically obtainable when there is an ideal power unit over the same period.

In terms of energy, the system use is justified, when $\boldsymbol{\pi}>1$, otherwise if $\boldsymbol{\pi}<1$, it serves no purpose to invest in its development.

Let the above suggested method be considered for specific energy sources. 


\subsection{Hydroelectric power plants (HPPs)}

The interval from the start of operation to overhaul should be taken as the design HPP operation period, and during further operation the time should be counted from the overhaul. In addition, determination of CRSEC during subsequent operation should involve overhaul costs rather than primary costs. For HPPs, with certain data correction, CRSEC can also be determined using formula (19), which will take the following form:

$$
\pi^{H P P}=\frac{Q_{1}^{H P P}}{Q_{p e c}^{H P P}}
$$

where $Q_{1}^{H P P}$ - energy supplied by HPP over the design period;

$Q_{p e c}^{H P P}-$ costs of primary energy obtained from an external source over the design period.

They are determined according to formula:

$$
Q_{p e c}^{H P P}=Q_{e q}^{H P P}+Q_{c a p}^{H P P}+Q_{o p}^{H P P}+Q_{o t h}^{H P P},
$$

where $Q_{e q}^{H P P}$ - primary energy costs to manufacture the equipment;

$Q_{c a p}^{H P P}$ - primary energy costs on capital construction, object equipment assembly and disassembly;

$Q_{o p}^{H P P}$ - primary energy operational costs;

$Q_{o t h}^{H P P}$ - other primary energy costs.

\subsection{Solar energy}

For helioplants, CRSEC is defined by formula:

$$
\pi^{H e l}=\frac{Q_{1}^{H e l}}{Q_{p e c}^{H e c}}
$$

where $Q_{1}^{H e l}$ - energy supplied by helioplant over the entire period of its operation;

$Q_{p e c}^{H e l}$ - costs of primary energy obtained from an external source over the entire period of its operation. They are defined as follows:

$$
Q_{p e c}^{H e l}=Q_{e q}^{H e l}+Q_{c a p}^{H e l}+Q_{o p}^{H e l}+Q_{o t h}^{H e l}
$$

where $Q_{e q}^{\mathrm{Hel}}$ - primary energy expended on manufacturing the equipment;

$Q_{\text {cap }}^{\text {Hel }}$ - primary energy expended on construction, assembly and disassembly of helioplant;

$Q_{o p}^{\mathrm{Hel}}$ - operational primary energy costs;

$Q_{\text {oth }}^{\mathrm{Hel}}$ - other primary energy costs.

\subsection{Wind energy}

For wind turbines, CRSEC is determined using the same method as described in the previous cases:

$$
\pi^{W}=\frac{W}{Q_{p e c}^{W}}
$$

where $\boldsymbol{Q}_{1}^{W}$ - energy obtained from wind turbine over its entire operation period;

$\boldsymbol{Q}_{\text {pec }}^{W}$ - costs of primary energy from an external source for wind turbine manufacture, construction, and operation. They are determined according to expression: 


$$
Q_{p e c}^{W}=Q_{e q}^{W}+Q_{c a p}^{W}+Q_{o p}^{W}+Q_{o t h}^{W}
$$

where $\boldsymbol{Q}_{\boldsymbol{e q}}^{W}$ - primary energy expended on manufacturing the equipment;

$\boldsymbol{Q}_{c a p}^{W}$ - primary energy costs for equipment assembly and disassembly;

$\boldsymbol{Q}_{\boldsymbol{o p}}^{\boldsymbol{W}}$ - operational primary energy costs;

$Q_{o t h}^{W}-$ other primary energy costs.

\subsection{Geothermal energy}

For geothermal power plants, CRSEC is determined using the same method as described in the previous cases:

$$
\pi^{G e o}=\frac{Q_{1}^{G e o}}{Q_{p e c}^{G e e}}
$$

where $\boldsymbol{Q}_{1}^{G e o}$ - energy obtained from geothermal power station over its entire operation period;

$\boldsymbol{Q}_{\text {pec }}^{G e o}$ - costs of primary energy obtained from an external source over the entire period of geothermal power station operation. They are defined as follows:

$$
Q_{p e c}^{G e o}=Q_{e q}^{G e o}+Q_{c a p}^{G e o}+Q_{o p}^{G e o}+Q_{o t h}^{G e o}
$$

where $\boldsymbol{Q}_{\boldsymbol{e q}}^{G e o}$ - primary energy expended on manufacturing the equipment;

$\boldsymbol{Q}_{\text {cap }}^{\text {Geo }}$ - primary energy costs for drilling a borehole, equipment assembly and disassembly;

$\boldsymbol{Q}_{\boldsymbol{o}}^{\mathbf{G e o}}$ - operational primary energy costs;

$\boldsymbol{Q}_{\text {oth }}^{\mathbf{G e O}}$ - other primary energy costs.

It is difficult to immediately and fully switch over to an energy method for evaluating the geothermal energy cost, but even a stepwise transition can provide a clear impression in a first approximation of the degree of effectiveness, which a particular system has.

\subsection{Waste recycling}

For waste recycling, CRSEC is determined using the same methods as those described in the previous cases:

$$
\pi^{\text {waste }}=\frac{Q_{1}^{\text {waste }}}{Q_{\text {pec }}^{\text {waste }}}
$$

where $\boldsymbol{Q}_{1}^{\text {waste }}$ - energy obtained from recycled waste over the entire period of recycling facility operation (when calculating it, the energy should also be taken into account, expended on removing metal, glass, and other materials from domestic waste);

$\boldsymbol{Q}_{\text {pec }}^{\text {waste }}$ - actual costs of primary energy obtained from an external source over its entire operation period. They are defined as follows:

$$
Q_{p e c}^{w a s t e}=Q_{e q}^{w a s t e}+Q_{c a p}^{w a s t e}+Q_{o p}^{w a s t e}+Q_{o t h}^{w a s t e}
$$

where $\boldsymbol{Q}_{\boldsymbol{e q}}^{\text {waste }}$ - primary energy expended on manufacturing the equipment;

$\boldsymbol{Q}_{\text {cap }}^{\text {waste }}$ - primary energy costs for construction, assembly and disassembly of recycling facility;

$\boldsymbol{Q}_{\boldsymbol{o p}}^{\text {waste }}$ - operational primary energy costs;

$\boldsymbol{Q}_{\text {oth }}^{\text {waste }}$ - other primary energy costs. 


\subsection{Biofuel production}

The formula to determine CRSEC as applied to biofuel production per 1 ha of land over a design period of 1 year is as follows:

$$
\pi^{b i o}=\frac{q_{1}^{b i o}}{q_{p e c}^{b i o}}
$$

where $\boldsymbol{q}_{\mathbf{1}}^{\boldsymbol{b i o}}$ - specific energy obtained from biofuel over the design period of production, $\mathrm{J} /($ ha year); $\boldsymbol{q}_{\text {pec }}^{\text {bio }}$ - costs of specific primary energy to produce biofuel over the design period, J/(ha year);

Actual energy costs are defined by the following formula:

$$
q_{p e c}^{b i o}=q_{e q}^{b i o}+q_{c a p}^{b i o}+q_{o p}^{b i o}+q_{o t h}^{b i o}
$$

where $\boldsymbol{q}_{\boldsymbol{e q}}^{\boldsymbol{b i o}}$ - specific primary energy expended on manufacturing the equipment;

$\boldsymbol{q}_{\text {cap }}^{\boldsymbol{b i o}}$ - costs of specific primary energy for constructing the object to reprocess biomass, assemble and dismantle its equipment;

$\boldsymbol{q}_{\boldsymbol{o p}}^{\boldsymbol{b i o}}$ - operational costs of specific primary energy for machinery, fertilizers, pesticides, etc. over the design period;

$\boldsymbol{q}_{\text {oth }}^{\text {bio }}$ - other specific primary energy costs.

Other costs should also include labour costs.

For heat pump installation (HPI) CRSEC is determined using the same method as described in the previous cases:

$$
\pi^{H P I}=\frac{Q_{1}^{H P I}}{Q_{p e c}^{H P I}}
$$

where $\boldsymbol{Q}_{1}^{H P I}$ - energy delivered to HPI consumer over the entire period of HPI operation;

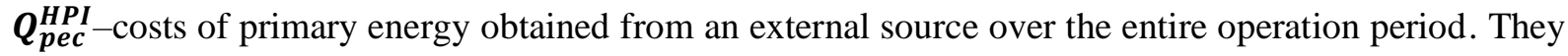
are determined as follows:

$$
Q_{p e c}^{H P I}=Q_{e q}^{H P I}+Q_{c a p}^{H P I}+Q_{o p}^{H P I}+Q_{o t h}^{H P I}
$$

where $\boldsymbol{Q}_{\boldsymbol{e q}}^{\boldsymbol{H} \boldsymbol{P I}}$ - primary energy expended on manufacturing the equipment;

$\boldsymbol{Q}_{c a p}^{H P I}-$ costs of primary energy over the entire operation period from assembling to disassembling HPI;

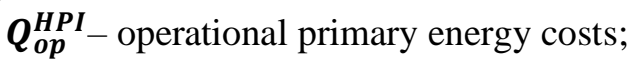

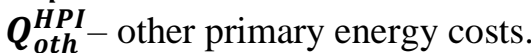

\subsection{Nuclear power plants (NPPs)}

For NPPs that utilise limited reserves of nuclear fuel, it is possible to define an energy breeding gain through formula (19):

$$
\pi^{N P P}=\frac{Q_{1}^{N P P}}{Q_{p e c}^{N P P}}
$$

where $Q_{1}^{N P P}$ - energy, obtained from NPP over the entire period of its operation; 
$Q_{p e c}^{N P P}$ - costs of primary energy obtained from an external source over the whole operation period. They are determined as follows:

$$
Q_{p e c}^{N P P}=Q_{e q}+Q_{c a p}^{N P P}+Q_{o p}^{N P P}+Q_{o t h}^{N P P}
$$

where $Q_{e q}$ - primary energy expended on extraction and preparation, transportation and storage, milling of uranium ore;

$Q_{c a p}^{N P P}$ - primary energy expended on construction of power plant and repository, assembly and disassembly of NPP equipment;

$Q_{O P}^{N P P}$ - operational primary energy costs for power plant and repository, including costs for extraction, transportation, ore preparation, and storage of radioactive production waste;

$Q_{o t h}^{N P P}$ - other primary energy costs.

Energy breeding gain largely depends on uranium content in ore and trouble-free NPP operation.

\section{DISCUSSIONS}

In the energy analysis of economic activity suggested by Charles Hall, there are two spelling variants and two values of EROEI abbreviation in English in the modern sense: if it is EROEI (energy returned on energy invested), it implies the ratio between obtained and invested energy; when it is EROI (energy return on investment), this is the ratio between obtained energy and investments. These ratios can accordingly be written as the following formulas:

$$
\operatorname{Er}=\frac{E_{2}}{E_{1}}
$$

and

$$
E \boldsymbol{i}=\frac{E_{2}}{\mathrm{C}}, \mathrm{J} / \text { rub. }
$$

where $E r-$ EROEI;

$E_{2}-$ energy obtained from fuel or a device transforming the Earth's, solar, etc. energy, J;

$E_{1}$ - energy expended to extract (produce) energy $E_{2}, \mathrm{~J}$;

$E i-$ EREI;

$C$ - means spent to extract (produce) energy $E_{2}$, rub.

Any predator as all living organisms, with no exceptions for salmon as well, is unable to expend more energy than food provides to him, i.e. all processes here occur according to the second thermodynamic law. Any living organism can be considered as a usual heat engine, functioning with less than 1 efficiency factor, since no organism can extract all the energy from food.\#

In a general case, the efficiency factor for predator over a fixed period will be defined by formula:

$$
\eta=\frac{E_{1(\tau)}}{E_{2(\tau)}}
$$

where $E_{1(\tau)}$ - energy expended by predator over time $\tau$;

$E_{2(\tau)}-$ energy obtained by predator from food over time $\tau$.

Predator, while eating food, can move, grow, and breed but is unable to generate energy. Hence, a concept of EROEI, when extended from predator to fuel extraction, should be considered differently. If in the first case the energy expended by predator is always less than the energy, he obtained by eating food, then in the second case, when it comes to extracting fuel, the energy obtained from fuel, is always greater than the energy expended on its extraction. If the total energy expended on fuel extrac- 
tion is equal to the energy contained in the extracted fuel, it makes no sense to extract fuel at a given field in terms of energy. In fact, EROEI thus interpreted is nothing but CRSEC. So, when utilising fossil fuel, CRSEC can be defined by formula:

$$
\pi=\frac{Q_{2}}{Q_{1}},
$$

where $Q_{2}$ - amount of all energy obtained at the field, J;

$Q_{1}$ - amount of energy expended over the period of carrying out all works at the field, J.

It should be noted that $\pi$ is greater than 1 , since $Q_{2}$ is not related to $Q_{1}$ through the second thermodynamic law, as the fuel extracted at the field, is an energy source, i.e. an energy carrier. And if $\pi$ is less or equal to 1 , this technological process becomes meaningless in terms of energy, regardless of whether it relates to helioplant or fossil fuel deposit.

In Russia, researchers under the guidance of Safronov A.F. address the problem of computing EROEI. They, in particular, present EROEI computation data for a number of energy resources, mostly with respect to American conditions obtained by Hall and revised by Richard Heinberg as of 2009. Thus, EROEI for the worldwide petroleum extraction amounts to 19 , for natural gas -10 , coal - 50, bituminous sands - 5.2-5.8, shale oil - 1.5-1.4, nuclear energy - 1.1-15, hydropower - 11-267, wind energy - 18, photovoltaics - 3.75-10, ethanol sugar cane - 0.8-1.7 (8-10 in Brazil), corn ethanol - 1.1-1.8, biodiesel - 1.9-9 (Safronov, 2010).

As fossil fuels are extracted, the value of their EROEI decreases due to various reasons, since prolific and accessible deposits are usually developed first. This trend is also seen in Russia, for which the numerical value of EROEI was determined for three years: 31.7 in 2005, 29.9 in 2007 and 29.5 in 2008, based on the data on direct joint energy expenditure when extracting oil and gas (Safronov, 2010).

For particular EROEI cases, numerical values of $E r$ will largely depend on how accurately $E_{1}$ was determined. Since during the development of some fields the energy obtained at other fields is utilised, inaccurately defined energy cost value may create an illusion about the field energy cost effectiveness. For example, energy costs associated with works on oil and gas extraction objects are provisionally divided into groups: capital, current, closure (Safronov, 2010). The respective work stages are construction, operation and closure of objects within a field.

EROEI will decrease with distance from a borehole and be defined by formula

$$
E r_{i}=\mu_{2 i} \cdot E r_{u c}
$$

At the point of the process cycle from extracting to using heat and electrical energy, where $E r_{i}$ will become equal to 1 , the energy value of this energy carrier ceases to exist. When exporting energy carriers, $E r_{i}$ can be defined to the country frontiers.

EROEI has not any significance for a seller of energy carriers, since their price is established by the market, where cheap fuel sets the pace. However, a seller's profit will be defined by EROEI value, i.e. the higher the costs, the lower the benefit.

Since both $\mu_{1 i}$ and $\mu_{2 i}$ are always less than 1, the value of $E r_{i}$, computed taking CBPEU into account, will be considerably lower than that obtained by formula (24). Allowing for CBPEU, formula (24) will be written as follows:

$$
E r=\frac{E_{2}}{\frac{E_{1}}{\mu_{1 i}}} \text { or } \boldsymbol{E r}=\frac{\mu_{1 i} \cdot E_{2}}{E_{1}}
$$


Time factor should be taken into account when computing EROEI for hydropower plants, helioplants, stations that use geothermal energy, etc. I.e., the ratio shall be taken between the energy obtained or supposed to be obtained over the whole operation period of a power unit or a facility, and the energy expended over the entire period: from commencement of works to complete disposition of a unit or facilities. CBPEU should be taken into consideration in both cases (Safronov, 2011).

There is no way to fully account for all energy losses in the absence of the corresponding data. Energy consumption during main process stages must be allowed for.

To gain a full knowledge of the energy value of energy resources when computing EROEI, the data on total energy costs need be used, with allowance for their depreciation while moving along the process flow, i.e. from fuel deposit to a consumer, defined by CBPEU.

It is important to change over to such calculation methods, which would allow determination of energy cost effectiveness of using a given fuel.

\section{CONCLUSIONS}

A complex method for determining CBPEU of power units will make it possible to reveal those particular processes, where energy losses are considerable, and where it is essential to enhance the quality of energy use first. To attain the stated objective, various economic measures need to be taken, which will result in increasing CBPEU, i.e. in improving a system capability without increasing fuel consumption, only at the expense of decreasing energy losses in irreversible processes occurred in the system.

Determination of energy breeding gain taking primary energy costs into consideration will enable comprehensive evaluation of a project's implementation potential regardless of its estimated parameters.

\section{REFERENCES}

Boltzmann, L. (1970). Articles and speeches. Moscow: Nauka.

Capellán-Pérez, I., Miguel, L.J., and de Castro, C. (2019). Dynamic Energy Return on Energy Investment (EROI) and material requirements in scenarios of global transition to renewable energies. Energy Strategy Reviews, 26, 100399.

Celi, L., Della Volpe, C., Pardi, L., and Siboni, S. (2018). A new approach to calculating the «corporate» EROI. Biophysical Economics and Resource Quality, 3, 15.

Cherevatskyi, D. (2017). EROI the Ukrainian coal. Ekonomicheskiy vestnik Donbassa (Economic Bulletin of Donbass), 4 (50), 20-31.

De Castro, C., and Capellán-Pérez, I. (2020). Standard, Point of Use, and Extended Energy Return on Energy Invested (EROI) from Comprehensive Material Requirements of Present Global Wind, Solar, and Hydro Power Technologies. Energies, 13 (12), 3036.

Fedorovsky, N.M. (1935). Classification of mineral resources according to their energy indices. Moscow-Leningrad.

Fersman, A.E. (1937). Geochemistry. Volume III. Leningrad: Khimteoret.

Fiapshev, A., Kilchukova, O., and Khamokov, M. (2017). Biogas unit for agricultural enterprises. Energy security and energy saving, 2, 27-29. 
Fiapshev, A., Kilchukova, O., Shekikhachev, Y., Khamokov, M., and Khazhmetov, L. (2018). Mathematical model of thermal processes in a biogas plant. In: ICRE 2018 International Scientific Conference 'Investment, Construction, Real Estate: New Technologies and Special-Purpose Development Priorities. MATEC Web of Conferences, 212, 010032, 1-13. https://www.matec-conferences.org

Global Warming of $1.5^{\circ} \mathrm{C}$. (2018). Special Report. Intergovernmental Panel on Climate Change, Geneva, Switzerland. https://www.ipcc.ch/sr15/

Hall, A.S. (2017). Will EROI be the primary determinant of our economic future? The view of the natural scientist versus the economist. Joule, 1, 635-638

Hall, Ch. (2008). Why EROI matters. The Oil Drum. http://www.theoildrum.com/node/3786

Järvensivu, P., Toivanen, T., Vadén, T., Lähde, V., Antti Majava, A., Jussi, T. (2018). Governance of Economic Transition. Global Sustainable Development Report 2019. https://bios.fi/biosgovernance_of_economic_transition.pdf

King Hubbert, M. (1956). Nuclear energy and the fossil fuels. Drilling and Production Practice. Washington: American Petroleum Institute

Kuznetsov, P.G. (1994). System of nutrition: common sense against genocide. Journal of interregional statesmanship, 5, 182-184

Marx, K. (1955-1981). Written works. Volume. 35. Moscow: Politizdat

Moriarty, P. and Honnery, D. (2019). Energy Accounting for a Renewable Energy Future. Energies, $12(22), 4280$

Podolinsky, S.A. (1880). Human work and its relation to energy distribution. Vol. IV-V. Moscow: Slovo

Raugei, M., Sgouridis, S., Murphy, D., Fthenakis, V. (2017). Energy Return on Energy Invested (ERoEI) for photovoltaic solar systems in regions of moderate insolation: A comprehensive response. Energy Policy, 102, 377-384

Safronov, A.F. (2010). EROEI as an indicator of the effectiveness of energy resources extraction and production. Drilling and Oil, 12, 48-51

Safronov, A.F. (2011). Methodology for calculating EROEI by the example of developing Sredneviluy gas-condensate field. Oil and Gas Engineering, 6, 197-209. http://www.ogbus.ru

Temukuyev, T.B. (2014). On the method of calculating EROEI allowing for coefficient of beneficial energy use. Economic sciences, 3 (112), 62-66.

Timiryazev, K.A. (1948). Sun, Life, and Chlorophyll. Selected works in 4 volumes. Public lectures, speeches, and scientific research. Moscow: Ogiz-selhozgiz.

Umov, N.A. (1916). Physico-chemical model of living matter. Collected works. Vol. III. Moscow: Typolithography of I.N. Kushnerev and K. http://eheritage.ru/ras/view/publication/general.html?id=46906367

Vernadsky, V.I. (1928). On objectives and organization of the USSR AS applied research work. Leningrad: , Publishing House of the USSR Academy of Science 